\title{
LA CASA DE LOS VIRREYES EN HUEHUETOCA
}

\author{
Por Manuel Romero de Terreros
}

Durante muchos años, un edificio en Huehuetoca, que todavia existc, aunque en estado de abandono, era conocido pomposamente como "La Casa de los Virreyes".

Nunca fue pródiga la naturaleza en aquel vetusto poblado del hoy Estado de México. Falto de agua y vegetación, Huehuetoca fue siempre un sitio triste por excelencia, y si alguna importancia tuvo antaño, era debido a que allí hacian escala las "diligencias", y otros vehículos de los tiempos pasados. Pero con la construcción de los ferrocarriles, desapareció aquel tránsito; y las numerosas revoluciones que asolaron al país, dejaron allí sus huellas. como lo atestiguan aún no pocos techos derruidos y paredes de adobe que rápidamente se desmoronan.

¿Cómo fue que en un lugar de ningunos atractivos tenía una casa nada menos que el primer funcionario de la Colonia, el virrey de la Nueva España? La explicación es bien sencilla si se reflexiona que, a relativamente corta distancia de la casa, fluia (a lo menos en tiempo de aguas) el río de Cuautitlán, que en seguida recuerda el famoso "desagüe de Huehuetoca", por medio del cual se luchó, durante casi tres siglos, por librar a México de las inundaciones que periódicamente afligían a los moradores de la capital del virreinato, y que preocuparon siempre a los gobernantes del pars, desde don Luis de Velasco hasta don Porfirio Díaz, durante cuyo gobierno de mando se dio término a tan importante empresa.

El ilustre marqués de Salinas fue el primero en romper la tierra con una azada, el 30 de noviembre de $1607,{ }^{1}$ y casi todos sus sucesores tomaron vivísimo interés en la obra.

Como muy a menudo los virreyes y otros altos personajes visitaban las obras del "desagüe de Huehuetoca", así vulgarmente llamado, se fabricó la casa que nos ocupa, tanto para alojar a los encumbrados huéspedes en sus viajes de inspección, cuanto para que sirviera de oficinas y almacenes, de la obra. Existe la tradición, muy verosimil por cierto, de que fue mandada construir por dicho don Luis de Velasco.

1 Memoria histórica, técnica y administrativa de las obras del desagüe del Valle de México, 1449-1900. México, 1902. 
¿Cuántas veces habrán pisado sus umbrales aquellos grandes señores que gobernaron la Nueva España, y aquellos ilustres ingenieros, como diriamos hoy, que se llamaron Enrico Martínez y Adrián Boot! |Cuántas discusiones habrán escuchado sus muros, acerca de si debía seguirse la ciclópea tarea del tajo de Nochistongo, de allí cercano, o emprender el canal de desagüe por otro rumbo, como al fin y al cabo se hizo en nuestros días!

No se puede afirmar que toda la casa date del siglo Xvir, pero sí es muy probable que la mayor parte que queda del edificio sea de la primitiva construcción, erigida quizás por el propio Enrico Martínez. ${ }^{2}$ De todas maneras, en julio de 1742 , se suscitó una disputa entre el famoso autor del Sagrario de México, y el "maestro de arquitectura" Miguel Custodio Durán, con motivo de la postura de cada uno, por su parte, hizo para terminar "la Casa de Huehuetoca", disputa que culminó con el fallo a favor de Durán. Pero éste no debe confundirse con Diego del mismo apellido, también "maestro de arquitectura", y probable autor de la iglesia de Santa Prisca, en Tasco. ${ }^{3}$ Ciertamente la Casa de Huchuetoca nunca reveló el menor asomo del arte de tan excelsos maes- ' tros.

Afectaba la Casa de los Virreyes la forma de un paralelogramo rectangular, y consistia en un amplio patio, que daba luz a las habitaciones circundantes; pero la parte más interesante de la casa era un portal al frente, que aún existe. Con vista al poniente, medía aproximadamente sesenta metros de largo por unos seis de fondo, y lo formaba una galería de doce arcos de medio punto, que descansaban sobre sencillas columnas de piedra; y se hallaba flanqueado, en cada extremo, por una torre que remataba en forma de campanario de dos cuerpos, sencilla composición que, en sus buenos tiempos, no debe de haber carecido de cierta gracia señorial.

Infortunadamente, los tres primeros arcos de la extremidad norte, fueron cegados (probablemente en el siglo xviri) y elevado su techo, para formar una capilla, a juzgar por la portada que se construyó dentro de la galeria, con vista al sur, y que durante mucho tiempo conservó su antiguo portón de madera, con casetones y peinazos de excelente diseño y buena ejecución. Pero el palacio virreinal, en épocas posterio-

2 Manuel Romero de Terreros. "Carta de Examen de Lorenzo Rodríguez." En Anales del Instituto de Investigaciones Estéticas. núm. 15. México, 1947.

a Manuel Toussaint. Tasco, su historia, sus monumentos, caracteristicas actuales y posibilidades turisticas. Editorial CVLTVRA. México, 1931. 


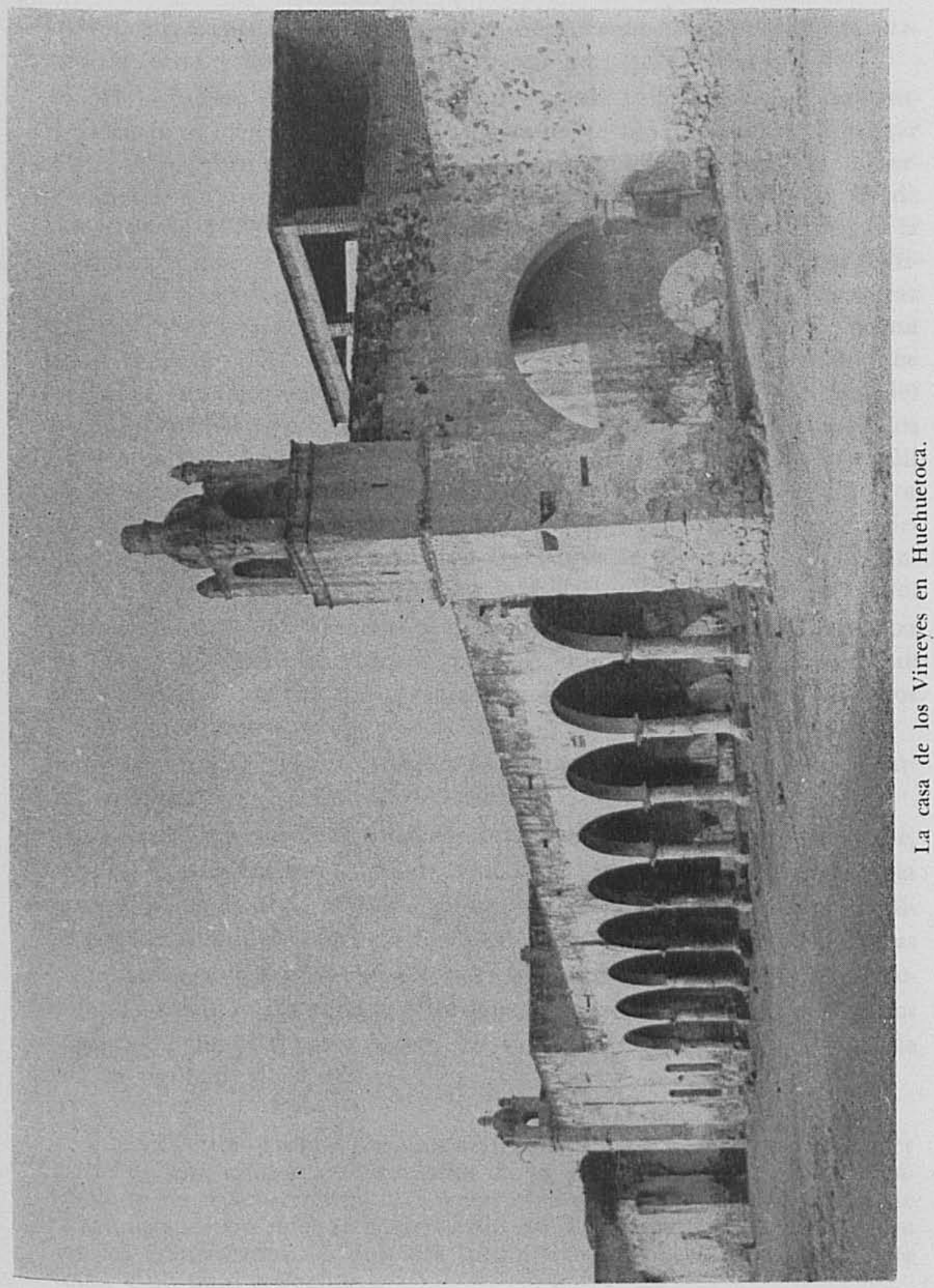


DOI: http://dx.doi.org/10.22201/iie.18703062e.1966.35.826 
res vino tan a menos, que esta capilla, después de haber servido de juzgado de letras y de cárcel, terminó... en una ipulqueríal

Sobre la puerta de entrada de la casa, queda una lápida con una inscripción, pero hace ya muchos años, solamente nos fue posible descifrar en ella el nombre de don Domingo de Trespalacios y Escandón, superintendente, y por lo tanto, factotum del "desagüe", desde el 30 de diciembre de 1742 hasta el 7 de abril de 1764. Esto nos hizo abrigar la sospecha de que la casa sufriera en su tiempo muy radicales modificaciones, sospecha que aumentó al penetrar en el patio y encontrar la mitad de él ocupada por las ruinas de un jardín típico de la décima octava centuria. Al ver los restos de pilastras, coronadas antaño por macetones, los pequeños arcos decorativos y la disposición toda del diminuto "pensil", recordamos en seguida el "estrado" de los antiguos jardines de San Angel y San Agustín de las Cuevas, o sea Tlalpan. E1 brocal de un pozo abandonado, una que otra planta que pugnaba por florecer en medio de aquella desolación, los derruidos pilares, nos hicieron más amable el recuerdo de don Domingo de Trespalacios y Escandón, si es que él, como es de suponerse, fue el autor de aquel patinillo.

Como dintel de una puerta-ventana, que se habría a este patio, figuraba una piedra con una inscripción, pero se veía a las claras que no fue éste su primitivo destino. Muy borrosa como estaba, solamente pudimos leer en ella lo siguiente:

"Governando... fran ... Duque de Alburquerque ... Cuellar ... Marqués de Cadereyta ... Conde de Ledesma..."

Este don Francisco Fernández de la Cueva, duque de Alburquerque, marqués de Cadereyta conde de Cuéllar y Ledesma, que gobernó la Nueva España de 1653 a 1660, era muy afecto a la arquitectura: modificó por completo el real palacio de México, y llenas están las crónicas de su tiempo del empeño que tomó en terminar la Catedral Metropolitana. También le interesaba el desagüe. Leemos en el Diario de Sucesos Notables de don Gregorio Martín de Guijo, correspondiente al año de 1658, lo siguiente:

Jueves 24 de octubre, después de haber asistido al acuerdo, el Virrey salió de esta ciudad en compañia de la Virreina y su familia, acompañado de todo el reino, a ir a ver el desagüe y visitar las minas de Pachuca; e hizo noche en el pueblo de Tlalnepantla, administración de los franciscanos... Volvióse luego, martes sobre tarde, 29 de este mes, y no pasó a Pachuca. 
A pesar de la redacción no muy clara de este párrafo del Diario, es evidente que los virreyes pasaron más allá de Tlalnepantla, en donde nada podían ver del desagüe; y la inscripción que hemos mencionado, se refiere indudablemente a la visita virreinal a Huehuetoca, punto de mayor interés por hallarse de allí cercanas las obras más importantes, especialmente la del tajo de Nochistongo. Es por lo tanto casi seguro, que la casa de este pueblo fue habitada durante algunos días por los fatuos duques de Alburquerque. La dilatada comitiva, encabezada por la altiva y mundana virreina marquesa de Cedereyta, habrá alegrado por breves horas las estancias de aquel "palacio", estancias que más tarde fueron empleadas para oficios tan ruines, que el viejo edificio parecería avergonzarse de su decadencia y buscar, en una muerte próxima, el olvido total de su antigua importancia. 